\section{独 ON} PSYCHIATRY AND MEDICINE.

\author{
DELIVERED BEFORE
}

the Southern Branch of the British Medical Association BY

HENRY DEVINE, O.B.E., M.D.Lond., F.R.C.P., MEDICAL SUPERINTENDENT, BOROUGH MENTAL HOSPITAL, PORTSMOUTH; CONSULTING PSYCHIATRIST, ROYAL VICTORIA HOSPITAL, NETLEY; LECTURER ON PSYCHOLOGY, MAUDSLEY NEUROLOGICAL HOSPITAL.

IT is the purpose of this address to draw attention to the isolation of psychiatry from general medicine, to point out its causes, and to make some suggestions as to how it may be remedied. Psychiatry might be described as occupying a position in relation to medicine as a whole analogous to that of a certified patient to the life of the community. It is on the outskirts of medicine and points of contact are few and far between, and it is this regrettable isolation which is no doubt responsible for the fact that psychiatry has failed to keep pace with progress to the same extent as other branches of medicine. The chief cause of this state of affairs is not far to seek; it is the result of the lunacy law, which, however useful it may be as an instrument of detention, is entirely out of harmony with modern psychiatric thought. In the first place, then, we must devote some attention to a consideration of the law and point out in what respects it requires amendment.

\section{Socral Aspects of the Lunacy Laws.}

Speaking generally, mental disorders are the only diseases in regard to which the English law lays down formalities which have to be complied with before a patient can obtain admission to a hospital or nursing home for treatment. There is no legal objection to treating a patient at home even if he be certifiable, but such a patient cannot, without infringement of the law, be received for payment into a public mental hospital, nursing home, general hospital, or private house until he has been certified, and, with the exception of urgency orders which are only valid for seven days, until a justice's order has been obtained for his reception and detention. In the case of a poorer person either removal to a Poor Law institution is necessary, or certification on the application of the relieving officer as a "pauper" patient.

There are, of course, no legal restrictions to the treatment of mental cases which are not certifiable, though the existing facilities for so doing are far from adequate; but where such cases are certifiable the formalities of the law have to be complied with before they can be treated away from home. Now as a result of these restrictions there is naturally great reluctance to admit any case, whether certifiable or not, to which the term " mental" can be applied, to a nursing home; and it must be admitted that the apprehension which is felt is thoroughly justified, as an apparently uncertifiable patient may at any time assume severe psychotic symptoms which render his continued detention illegal. Confronted with the difficulty of removing a patient to a nursing home, the practitioner has to consider the possibilities of treatment at home. In some cases this is impossible, and in the majority it is undesirable for both the patient and his relatives. It is a difficult matter to adjust to the whims, oddities, fancies, and unpredictable behaviour of the mentally disordered patient, and one invariably finds that the presence of such a person produces a state of tension, fatigue, and anxious expectation amongst the other members of the family. In any case, the nursing of a mental patient in a private house is a matter of considerable difficulty, and unless a nurse has had experience in mental work she is scarcely fitted to undertake this type of sick-nursing. In view of the large number of mental patients in need of nursing and treatment it is much to be hoped that more nurses will endeavour to obtain a double qualification.

In a number of cases, therefore, the question of certification and removal to a mental hospital has to be considered. Such a proposal usually causes the greatest consternation and distress, and often meets with the opposition of the whole family. In many cases the practitioner hesitates even to use the term "mental" and employs the more palatable but incorrect one " nerves," because he knows that any suggestion that the mind is disordered is liable to provoke an attitude of resentment and disbelief, due, of course, to the excessive dread of insanity, asylums, and certification. The extreme degree of psychic blindness exhibited by the relatives of a person suffering from mental illness is almost unbelievable, and there is probably greater resistance to facing the realities of the situation in mental disease than that manifested in any other malady. Irrational as such an attitude may be, it is one with which we can fully sympathize. Though we, as psychiatrists, who live our lives in an atmosphere of psychic abnormality, regard our patients as naturally as if they were the subjects of physical disorder, society as a whole does not so regard them, but submits not only them, but their families as well, to an insidious social censorship. One cannot deny that it is a definite social disadvantage to have or have had a parent who has been certified, and I have frequently observed disastrous effects resulting from the feeling of biological inferiority-often unjustified-which this situation creates. For this reason the incidence of insanity in the family is concealed more closely than any other "skeleton in the cupboard," and it is quite understandable that families should be anxious to avoid certification, since it imposes the official stamp of lunacy upon one of its members, and, indirectly, upon the whole family group. We are thus faced with the curious fact that the hospitals provided by the community for the treatment of mental disorders are the very last places to which it is considered desirable to send patients suffering from these illnesses. The asylum is regarded as a last resort, and treatment therein is delayed as long as possible.

Now it does not follow that, because there are sentimental objections to certification on the part of the public, this procedure is not beneficial and necessary both for the protection of the community and for ensuring the adequate care of those who are unable to care for themselves. There will, of course, always be a number of persons who, from unsoundness of mind, need care, control, and treatment, and it is obvious that no person should be deprived of his liberty against his will other than by a legal process. The lunacy laws were designed to prevent illegal detention, to ensure humane treatment, and to obviate the possibility of misusage of the person and estate of the mentally unsound, and since their inception I think we may say that these aims have been in a large measure realized. While, then, we recognize the past and present value of the lunacy laws, there is no doubt that they have become a barrier to the effective treatment of mental disorder in its most curable stages, and I have not yet met a practitioner who did not consider that provision should be made for the observation and treatment of mental patients without certification, and that the law should be amended to make this possible.

It must be remembered that the lunacy laws were formulated at a time when not only the insane, but delinquents and paupers as well, were treated with great harshness, and when, so far as the insane were concerned, treatment as now understood was practically unknown. The conditions which made such stringent laws necessary no longer, of course, exist. The existing law portrays almost entirely the legal attitude of mind to the insane, and the certified person is not regarded in the eyes of the law as a patient in the true sense of the word. The mental patient is " put away" not primarily for the purposes of treatment, but because he cannot be " managed" in any other way. In effect, the attitude taken by the law to the subject of a psychosis is that he shall not be treated in a mental hospital unless circumstances force it, nor shall he remain if it is possible for him to be outside. What we obviously need is a change in the law which will encourage mental patients to obtain treatment when it is medically rather than legally necessary, and to remain under care as long as they need a hospital régime.

It is unnecessary to discuss in detail the changes in the law which are generally deemed to be so urgently needed. The subject is full of technical difficulties, but experience shows that the principle that all certifiable patients must 
necessarily be certified to obtain hospital treatment is capable of considerable modification. Many cases at present certified could be treated on a voluntary basis, and those who are delirious and confused, and are thus incapable of volition, could often be safely dealt with by a simple procedure of notification similar to that which obtains in Scotland. The Board of Control, psychiatrists, and, I think I may say, the medical profession generally, are of the opinion that the care and treatment of the insane are hampered by unnecessary legal restrictions and that an amendment of the law is long overdue. I have no doubt the Royal Commission on Lunacy Administration will formulate proposals which will pave the way to reform in the existing methods of dealing with early and recoverable cases of mental disorder. At present we lack experience of the extent to which it is possible to treat the pychoses in open wards without certification, and for this reason legal innovations will naturally have to be based on a policy, not only progressive, but prudent as well.

Effects of Lunacy Laws on Psychiatry.

So far we have considered more particularly the social aspects of the lunacy laws, and we have aimed to show how early treatment is handicapped by legislation because families are reluctant to allow their relatives to be certified. It now remains to consider the effects of these laws on psychiatry as a branch of medicine, and I would first point out that if mental medicine is to progress it must cease to be the exclusive domain of the psychiatrist. What is most needed at the present time is full co-operation between psychiatrists and the medical profession as a whole. The former cannot be expected to solve unaided the manifold and complex problems of mental disease which are now recognized to include all those presented to the observer in general medicine. The factors entering into the causation of abnormal behaviour-the subject-matter of psychiatryare extremely complex, and their elucidation requires the services of, not only the clinical psychiatrist, but the physician, the pathologist, specialists in all branches of medicine, biologists, educationists, and psychologists-a truly formidable list.

It is necessary to grasp the notion that a person's behaviour-that is to say, his reaction to his environment - cannot be directly correlated with any cause. Our actions at any given moment are determined by a myriad of past happenings, both individual and racial, the external situation at the time of its performance, and the present physical state of the organism. Any attempt to explain our actions by isolated causes is deceiving, and the failure to recognize this in the sphere of psycho-pathology creates much misunderstanding and hampers progress. Thus disputes as to whether insanity is due to inherent or acquired causes leads nowhere, as the influence of these factors cannot be estimated quantitatively. We cannot say how much of a person's behaviour is "due" to heredity and how much to environment, and the extent to which emphasis is laid on one or the other of these influences is largely dependent upon the observer's own psychology; that is to say, he will bring into the foreground the causal factors in which he is personally most interested. It is obvious that neither factor can be eliminated, and both have to be considered in any attempt to prevent the incidence of mental disorder.

It would be wrong to ignore the fact that predisposition plays a part in the production of abnormal mental states. There has been a tendency, however, to overemphasize this factor. It is now generally recognized that the causes of disease included under the term "predisposition" are represented by negative factors rather than active causative agents. Predisposition is indicated by the fact that one individual, having either inherited or acquired a greater deficit in a given potential, will require less of an exciting factor to interfere with normal function or give rise to a condition of abnormal function (A. C. Buckley). It must be recognized, however, that whether or not a child possess an inborn "sensitivity" the association from birth with psychopathic parents is often responsible for the development of an abnormal reaction to life. As Kempf points out, an unhappy parent, conventional and miserable because of his affective repressions, tends insidiously to make thuse about him cause repressions of all affective interests that tend to arouse the intolerable, repressed wish in himself. In this manner such adults incessantly influence the defenceless child to make repressions of the very affective functions whose freedom of expression is absolutely essential to the development of a healthy personality. Kempf presents a series of families to show how the abnormal affective adjustments in a parent influence a son with excellent functional capacities, and the son in turn influences the grandson. These relations are cultivated through innumerable experiences, day by day, extending throughout the growth of the child. Janet also has called attention to the fact that the presence of a neuropathio individual in a family almost invariably results in nervous reactions on the part of the whole household. He shows, moreover, that the explanation of these cases on the lines of heredity is often inadmissible, in so far as there is often no blood relationship between the affected individuals. It is thus clearly impossible to state with assurance the extent to which inherent predisposition and subtle and intangible environmental influences are respectively respon. sible for abnormal mental reactions, even when there is a definite family history of insanity or neurosis. The question has important practical bearings, for when the practitioner meets with a young patient in whom some inherent "sensitivity" is to be suspected, he may often do much good by recommending removal to school if there is reason to suppose that a psychopathic parent is exerting an unfavourable influence.

I have devoted some attention to hereditary influences because of the popular belief that insanity is necessarily the expression of degeneracy in the family. It must be pointed out that many psychoses occur, however, in persons in whom no family history of insanity or other forms of psychic inferiority is discoverable; these are the accidental psychoses-that is to say, those which are cured without leaving any morbid traces, and which constitute only an episode, more or less brief, in the life of man. In actually treating a given case I need hardly say that the existence or otherwise of a morbid predisposition is a matter of purely academic interest, as it obviously will tend to operate after recovery as a causal factor in further attacks. The exciting causes of a psychosis are numerous, and may be classified under the headings of psychic, toxic, exhaustive, organic, and traumatic. It is these physical factors which afford indications for treatment of the recent and acute psychoses. I wish to emphasize particularly the fact that the effective methods of treatment in these conditions are those which originate from general pathology-namely, those which aim to combat the processes of infection, autointoxication, and inanition. I am fully alive to the interest and importance of psychological studies of the insane, but developed psychoses are seldom amenable to direct psychotherapeutic approach, and successful treatment must be based on the principle that the symptoms observed are the expression of a morbid state of the physical organism. A knowledge of general pathology, of pathological anatomy, and of internal medicine are to-day indispensable for the efficient treatment of mental disorder. In spite of a personal interest in psychological problems $I$ am of the opinion that the problems of psychiatry will only be solved by approaching them from the standpoints of biology and pathology, and I have no doubt that this branch of medicine will tend to develop more and more in those directions.

\section{How Progress will Come About.}

In the light of these observations it is olear that psychiatry can only advance by complete co-operation with general medicine. In order that this may be effected the existing mental hospitals obviously need, besides the fulltime medical officers, a consulting staff drawn from the local hospital whose advice can be obtained when necessary. It is essential, for instance, that a psychiatrist, whose experience of obstetrics and gynaecology must necessarily be slight, should have the opportunity of consulting with a specialist in this subject in, at the very least, every case of puerperal insanity admitted to the institution. During the war I was in charge of a section for mental cases in $a$ hospital admitting every type of illness occurring amongst 
the soldiers. The staff naturally consisted of specialists in every branch of medicine, and I then discovered how advantageous it was to my mental patients to refer them to other members of the medical unit for advice in regard to any physical disabilities from which they suffered. My own knowledge was enriched, and the patient benefited by the consultations. Such a privilege should be made available in every mental hospital, and already is in many of them.

The complete union of psychiatry and general medicine can only be effected when the existing lunacy laws are so amended as to make it possible to treat the psychoses without legal formalities apart from institutions devoted exclusively to these disorders. The exclusion of mental cases from the great teaching hospitals which have special wards for every other type of illness is largely responsible for the divorce between psychiatry and medicine. That it is quite possible to treat many forms of psychosis in a hospital ward was demonstrated in an article in the British MEDICAL Joursal by Dr. Comrie. ${ }^{1}$. Under present conditions of treatment the term "insanity" has come to carry with it the suggestion of chronicity, detention, legal pitfalls, huge institutions filled with incurable patients, degeneracy, and forms of illness for which " nothing can be done." At the outset of a student's career an impression of this kind must ineritably be created in his mind from the fact that he learns nothing of the psychoses, apart from his few visits to the asylum, where the majority of cases produced for demonstration are of the chronic and incurable type; and in his subsequent career, whether as specialist or general practitioner, he takes no part in the treatment of the psychoses which reach any degree of intensity. An entirely fresh point of view would be gained if in his daily work he came into contact with cases of mental disorder. He would learn, above all things, that many morbid mental states are due to the same pathological conditions as are the symptoms of the various svistemic diseases, and amenable to the same methods of treatment. In the out-patient department, moreover, he would see a type of case which he will be called upon to deal with daily in his consulting room, and gain some knowledge of the treatment of the psychoneuroses-conditions which will bulk largely in his practice.

Similarly, in every urban area provision should be made for the treatment of the psychoses in their acute and early stages, and it is much to be hoped that this will be divorced entirely from the Poor Law. There is no possible reason why mental disorder should be tainted with pauperism as it is at present. The municipal health authorities which now deal with fevers and tuberculosis should obriously be entirely responsible for the care of the mentally sick who require in-patient treatment. With a suitable alteration of the law it should be possible also to treat certain certifiable cases by a simple system of notification in nursing homes. These more enlightened methods would naturally fit in with the doctor's experience as a student, and make it much easier to deal with mental cases to the satisfaction of the relatives.

I have aimed to show that if psychiatry is to progress it can no longer remain an isolated specialty; the solution of its problems requires the full co-operation of workers in erery sphere of medicine, and this must naturally include those who are concerned in the prevention rather than the cure of disease. Mental hygiene cannot be dissociated from physical or general hygiene. A French psychiatrist has expressed the view that the causation of mental affections is dominated by three great social scourges: tuberculosis, alcoholism, and syphilis. These, he feels, are the chief infections whose influence is felt in the production of mental disorder, not only in its subjects but in the descendants. Certainly it is to-day firmly established that we profit, both mentally and physically, from the good health of our ancestors, and it is also equally true that we are the rictims of their maladies, and more especially their chronic infections. The endeavours of our medical officers of health to stamp out syphilis would, if successful, considerably diminish the incidence of admissions to our asylums and would probably diminish the occurrence of

2 British Medical Journal, September 27th, 1924, p. 551. mental weakness in the coming generations. Here, also, educationists and religious teachers have a serious responsibility, and there should be no hesitation in teaching young people the elementary facts of sexual hygiene. The subject of prevention is, of course, inexhaustible, and I can do no more than mention the fact that the present and future mental health of the community is closely connected with everything concerning the general standard of physical health and the conditions under which the people live.

It will be a long time before the prejudices which surround the subject of mental disorder are dissipated. We look forward to the time, however, when the public learn to regard this disease as naturally as any other, and when they learn that it is produced by causes similar to those which are responsible for physical maladies. If medical practitioners were consulted by their patients when the first symptoms of mental disorder appeared, I am sure that ordinary physical remedies, rest, and psycho-therapeutic conversations which would enable patients to unburden their minds, would arrest many cases which now drift into serious states before advice is taken. It is much to be hoped, moreover, that when hospital care is considered necessary mental patients will be as willing as the subjects of physical illness to undergo in-patient treatment without apprehension and a sense of social disgrace, whether it be in the wards of a general hospital, special clinics for the treatment of uncertified cases, or separate pavilions connected with urban mental hospitals. The future of the nation is ultimately dependent upon a healthy and vigorous mental reaction on the part of its citizens, and for this reason no effort should be spared to raise the general standard of mental health.

\section{THROMBO-ANGIITIS OBLITERANS.}

$$
\text { BY }
$$

E. D. TELFORD, F.R.C.S.

PROFESSOR OF SYSTEMIATIC SURGERY, UNIVERSITY OF MANCHESTER; AND

JOHN S. B. STOPFORD, M.D., PROFESSOR OF ANATOMY, UNIVERSITY OF MANCHESTER. (With Special Plate.)

First recognized in 1879 by v. Winiwarter and described by him as endarteritis obliterans, this disease has, during recent years, been more fully described by Buerger ${ }^{1}$ of New York, who has given it the name of thrombo-angiitis obliterans. This name is the more accurate, because the disease is prone to involve veins as well as arteries.

The condition appears to have received little attention in this country. It can, however, hardly be rare, since no fewer than four cases have occurred in the practice of one of us within the last twelve months. It is with the object of drawing more widespread attention to this very grave disease that the following four cases are reported in considerable detail, together with the histological findings in the three cases which came to amputation on account of gangrene.

A study of Buerger's cases shows that the broad clinical features of the discase are as follows: It is a disease of the larger blood vessels which, although of unknown origin, shows the histological features of an inflammatory lesion. The vessels mainly affected are the larger arteries of the limbs, but the disease is seen also to some extent in the veins. Thrombosis occurs and is followed by organization of the clot. This produces grave embarrassment of the circulation, alleviated to a variable extent by the usual canalization of the fibrous tissue.

The disease occurs almost exclusively in males (99 per cent. in Buerger's cases), and the onset is commonly in the third decade. The lower limbs are affected much more commonly than the upper: it is the rule for the discase to begin in one lower extremity and to appear in the opposite limb at a date which may be from one to four years later than the first onset.

The disease produces symptoms such as would be cxpectid in a limb in which the arterial circulation is being carried on only with the utmost difficulty. The first symptom to attract attention is pain, produced and increased by 